\title{
Subunit Principle of Vulvar Reconstruction: Algorithm and Outcomes
}

\author{
Bien-Keem Tan ${ }^{1}$, Gavin Chun-Wui Kang ${ }^{1}$, Eng Hseon Tay ${ }^{2}$, Yong Chen Por ${ }^{3}$ \\ ${ }^{1}$ Department of Plastic, Reconstructive and Aesthetic Surgery, Singapore General Hospital, Singapore; ${ }^{2}$ Thomson Women Cancer Centre, \\ Singapore; ${ }^{3}$ Department of Plastic, Reconstructive and Aesthetic Surgery, KK Women's and Children's Hospital, Singapore
}

Background Vulvar defects result chiefly from oncologic resection of vulvar tumors. Reconstruction of vulvar defects restores form and function for the purpose of coitus, micturition, and defecation. Many surgical options exist for vulvar reconstruction. The purpose of this article is to present our experience with vulvar reconstruction.

Methods From 2007 to 2013, 43 women presented to us with vulvar defects for reconstruction. Their mean age at the time of reconstruction was 61.1 years. The most common cause of vulvar defect was from resection of vulvar carcinoma and extramammary Paget's disease of the vulva. Methods of reconstruction ranged from primary closure to skin grafting to the use of pedicled flaps.

Results The main complications were that of long term hypertrophic and/or unaesthetic scarring of the donor site in 4 patients. Twenty-two patients (51\%) were able to resume sexual intercourse. There were no complications of flap loss, wound dehiscence, and urethral stenosis. Conclusions We present a subunit algorithmic approach to vulvar reconstruction based on defect location within the vulva, dimension of the defect, and patient age and comorbidity. The gracilis and gluteal fold flaps are particularly versatile and aesthetically suited for reconstruction of a variety of vulvar defects. From an aesthetic viewpoint the gluteal fold flap was superior because of the well-concealed donor scar. We advocate the routine use of these 2 flaps for vulvar reconstruction.

Keywords Vulvar / Carcinoma / Surgical flaps
Correspondence: Bien-Keem Tan Department of Plastic, Reconstructive and Aesthetic Surgery, Singapore General Hospital, Outram Road, Singapore 169608

Tel: $+65-63214686$

Fax: $+65-62259340$

E-mail: bienkeem@gmail.com

Received: 5 Jun 2014 • Revised: 11 Jul 2014 • Accepted: 11 July 2014

pISSN: 2234-6163 • elSSN: 2234-6171 • http://dx.doi.org/10.5999/aps.2014.41.4.379 • Arch Plast Surg 2014;41:379-386

No potential conflict of interest relevant to this article was reported.

\section{INTRODUCTION}

Vulvar defects result chiefly from oncologic resection. Vulvar cancer comprises $5 \%$ of all female genital cancers and $1 \%$ of all female malignancies. The worldwide incidence of vulvar cancer peaks at 65 to 70 years of age and has been increasing in developed countries [1]. In Singapore, squamous cell carcinoma and vulvar intraepithelial neoplasia are the most common histological types of vulvar cancer [2]. The mainstay of treatment for vulvar cancer is wide surgical resection and radiation if necessary. Extramammary Paget's disease of the vulva (vulvar intraepithelial adenocarcinoma) is another common vulvar tumor treated with wide local excision [3]. Without reconstruction, surgical resection would result in mutilation and poor wound healing of the perineum, delaying delivery of any requisite adjuvant radiotherapy.

Reconstruction aims to restore anatomy and function of the external female genitalia, facilitating preservation of normal 
body image, sexual function, and micturition and defecation functions. The purpose of this paper is to describe our experience in 43 consecutive patients and to propose an algorithmic approach to vulvar reconstruction based on our experience.

\section{METHODS}

Forty-three patients underwent vulvar defect reconstruction between 2007 and 2013. Their mean age at time of surgery was 61.1 years (range, 35 to 83 years). The underlying vulvar conditions are summarized in Table 1 . The most common pathological conditions in our series were vulvar carcinoma and extramammary Paget's disease of the vulva (86\%).

There were 22 unilateral and 21 bilateral defects (Table 1). Defects were empirically classified as small defects (those which may be closed directly with undermining or with local flaps), medium defects (primary closure of these would lead to severe distortion of the perineum), and large defects (these cannot be closed directly without risk of dehiscence). Among unilateral defects there were 7 small defects ( 64 to $\left.84 \mathrm{~cm}^{2}\right), 10$ medium defects $\left(104\right.$ to $126 \mathrm{~cm}^{2}$ ), and 5 large defects $\left(150\right.$ to $260 \mathrm{~cm}^{2}$ ). Among bilateral defects there were 2 medium defects (104 to $144 \mathrm{~cm}^{2}$ ) and 19 large defects $\left(165\right.$ to $440 \mathrm{~cm}^{2}$ ). Fifty per cent of patients who had large defects required groin node dissection. The mean follow-up period was 30.2 months (range, 24 to 38 months).

The main flaps used (Table 1) included the gracilis flap $(\mathrm{n}=$
24), the gluteal fold flap $(n=7)$, the medial thigh flap $(n=5)$, and the vertical rectus abdominis myocutaneous (VRAM) flap $(\mathrm{n}=3)$.

The method of reconstruction and choice of flap depended on the extent and location of the vulvar defect (Fig. 1). From the lithotomy perspective the vulva could be divided into three subunits. The upper third subunit consists of the mons pubis extending into the labia; the middle third is the labia proper; and the lower third consists of the vaginal orifice and perineum. For instance (Fig. 1), gluteal fold transposition flaps comfortably reached the middle third but fell short of the upper third. Likewise, upper third defects were easily covered by abdominal local flaps but these could not reach posteriorly. Other subunits included the vaginal walls and the periurethral area which are deeper.

\section{Surgical technique}

Flap elevation techniques for the above flaps are well-established and we raised them in the standard fashion. Special attention was paid to the following: 1) After resection in the lithotomy position with the legs supported by Allen Yellofin stirrups, the patient was repositioned. The stirrups were extended to straighten the knees and the entire lower limbs were free-draped for added mobility (Fig. 2). We ensured the stirrups were hinged in a manner that allowed full adduction at completion of surgery. The lower buttocks were pulled over the edge of the operating table with the patient resting on the upper sacrum if gluteal fold flaps were planned. This saved turning the patient twice. This setup was
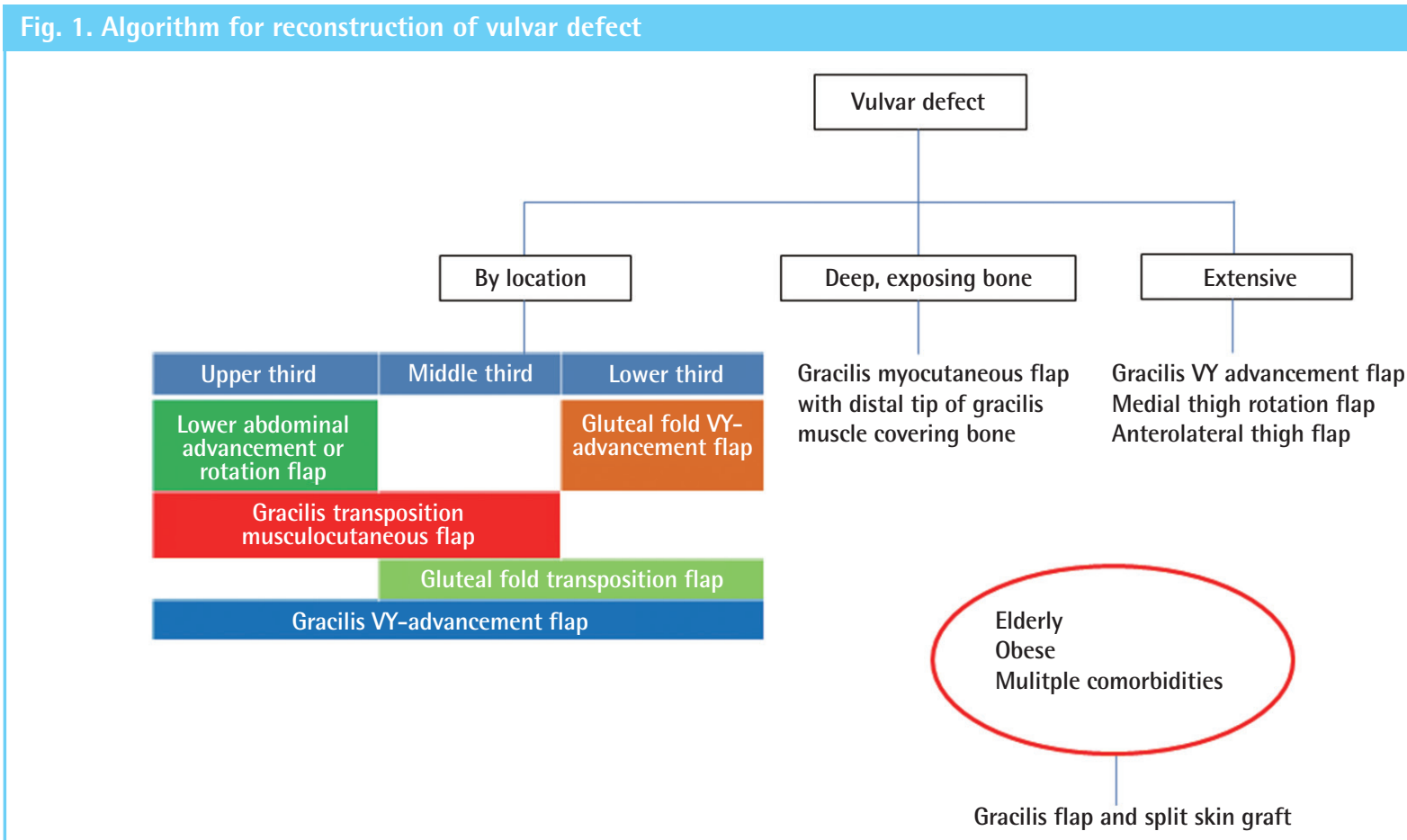
Table 1. Please write a short heading

\begin{tabular}{|c|c|c|c|c|c|c|}
\hline Case & $\begin{array}{l}\text { Age } \\
\text { (yr) }\end{array}$ & Diagnosis & $\begin{array}{l}\text { Defect } \\
\text { type }\end{array}$ & $\begin{array}{l}\text { Defect size } \\
\quad\left(\mathrm{cm}^{2}\right)\end{array}$ & Surgery & Complication \\
\hline 1 & 61 & Extramammary Paget's disease & Unilateral & 84 & Left gracilis muscle flap and split skin graft & Nil \\
\hline 2 (Fig. 4) & 74 & Squamous cell carcinoma vulva & Unilateral & 105 & Left gracilis myocutaneous transposition flap & Nil \\
\hline 3 & 84 & Extramammary Paget's disease & Unilateral & 84 & Left gracilis VY-advancement flap & Nil \\
\hline 4 & 71 & Extramammary Paget's disease & Unilateral & 135 & Left vertical rectus abdominis myocutaneous flap & Superficial tip necrosis of flap \\
\hline 5 & 56 & Extramammary Paget's disease & Unilateral & 225 & Local advancement rotation flap & Nil \\
\hline 6 & 58 & Dermatofibrosarcoma protuberans & Unilateral & 144 & Local advancement rotation flap & Nil \\
\hline 7 & 66 & Extramammary Paget's disease & Unilateral & 66 & Primary closure & Nil \\
\hline 8 & 67 & Vulvar nevus & Unilateral & 64 & Primary closure & Nil \\
\hline 9 & 44 & Chronic vulvar sinus & Unilateral & 70 & Primary closure & Cellulitis \\
\hline 10 & 66 & Necrotizing Fasciitis & Unilateral & 70 & Primary closure and skin graft & Cellulitis \\
\hline 11 (Fig. 7) & 63 & Extramammary Paget's disease & Unilateral & 150 & Right gluteal fold transposition flap & Nil \\
\hline 12 & 60 & Extramammary Paget's disease & Unilateral & 260 & Right gluteal fold VY-advancement flap & Nil \\
\hline 13 & 54 & Squamous cell carcinoma vulva & Unilateral & 108 & Right gluteal fold VY-advancement flap & Nil \\
\hline 14 & 35 & Squamous cell carcinoma vulva & Unilateral & 144 & Right gluteal fold VY-advancement flap & Nil \\
\hline 15 & 73 & $\begin{array}{l}\text { Metastatic adenocarcinoma from } \\
\text { endometrial primary }\end{array}$ & Unilateral & 84 & Right gracilis muscle flap and split skin graft & Nil \\
\hline 16 & 60 & Extramammary Paget's disease & Unilateral & 78 & Right gracilis muscle flap and split skin graft & Nil \\
\hline 17 (Fig. 9) & 83 & $\begin{array}{l}\text { Extramammary Paget's disease } \\
\text { and invasive adenocarcinoma }\end{array}$ & Unilateral & 126 & Right gracilis muscle flap and split skin graft & Nil \\
\hline 18 (Fig. 3) & 61 & Squamous cell carcinoma vulva & Unilateral & 72 & Right gracilis myocutaneous transposition flap & Nil \\
\hline 19 & 65 & Squamous cell carcinoma vulva & Unilateral & 104 & Right gracilis VY-advancement flap & Nil \\
\hline 20 & 66 & Mucinous carcinoma & Unilateral & 72 & Right medial thigh rotation flap & Hypertrophic scarring of donor site \\
\hline 21 & 67 & Extramammary Paget's disease & Unilateral & 150 & Right medial thigh rotation flap & Hypertrophic scarring of donor site \\
\hline 22 (Fig. 6) & 35 & Sarcoma & Unilateral & 160 & $\begin{array}{l}\text { Right stoma, left vertical rectus abdominis } \\
\text { myocutaneous flap }\end{array}$ & Cellulitis \\
\hline 23 & 70 & Extramammary Paget's disease & Bilateral & 144 & Bilateral gluteal fold transposition flap & Nil \\
\hline 24 (Fig. 8) & 51 & Extramammary Paget's disease & Bilateral & 324 & Bilateral gluteal fold VY-advancement flap & Nil \\
\hline 25 & 59 & Extramammary Paget's disease & Bilateral & 225 & Bilateral gluteal fold VY-advancement flap & Nil \\
\hline 26 & 69 & Extramammary Paget's disease & Bilateral & 440 & Bilateral gracilis muscle flap and split skin graft & Nil \\
\hline 27 & 58 & Squamous cell carcinoma vulva & Bilateral & 182 & Bilateral gracilis muscle flap and split skin graft & Nil \\
\hline 28 & 78 & $\begin{array}{l}\text { Metastatic clear cell carcinoma } \\
\text { from urethral primary }\end{array}$ & Bilateral & 182 & Bilateral gracilis muscle flap and split skin graft & Nil \\
\hline 29 & 76 & $\begin{array}{l}\text { Extramammary Paget's disease } \\
\text { and invasive adenocarcinoma }\end{array}$ & Bilateral & 221 & Bilateral gracilis muscle flap and split skin graft & Nil \\
\hline 30 & 68 & Extramammary Paget's disease & Bilateral & 104 & Bilateral gracilis muscle flap and split skin graft & Nil \\
\hline 31 & 51 & Extramammary Paget's disease & Bilateral & 196 & Bilateral gracilis VY-advancement flap & Nil \\
\hline 32 & 40 & $\begin{array}{l}\text { Recurrent squamous cell } \\
\text { carcinoma vulva }\end{array}$ & Bilateral & 225 & Bilateral gracilis VY-advancement flap & Cellulitis \\
\hline 33 & 63 & Squamous cell carcinoma vulva & Bilateral & 240 & Bilateral gracilis VY-advancement flap & Nil \\
\hline 34 & 60 & Extramammary Paget's disease & Bilateral & 225 & Bilateral gracilis VY-advancement flap & Nil \\
\hline 35 & 55 & Squamous cell carcinoma vulva & Bilateral & 165 & Bilateral gracilis VY-advancement flap & Nil \\
\hline 36 (Fig. 5) & 60 & Extramammary Paget's disease & Bilateral & 400 & Bilateral gracilis VY-advancement flap & Nil \\
\hline 37 & 56 & Extramammary Paget's disease & Bilateral & 180 & Bilateral medial thigh rotation flap & Hypertrophic scarring of donor site \\
\hline 38 & 49 & Squamous cell carcinoma vulva & Bilateral & 200 & $\begin{array}{l}\text { Left anterolateral thigh pedicled flap and split } \\
\text { skin graft }\end{array}$ & Nil \\
\hline 39 & 60 & Extramammary Paget's disease & Bilateral & 210 & $\begin{array}{l}\text { Right gracilis VY-advancement flap, left gracilis } \\
\text { muscle and split skin graft }\end{array}$ & Nil \\
\hline 40 & 66 & Extramammary Paget's disease & Bilateral & 240 & $\begin{array}{l}\text { Right gracilis VY-advancement flap, left medial } \\
\text { thigh rotation flap }\end{array}$ & Anal contracture \\
\hline 41 & 51 & Clear cell carcinoma & Bilateral & 324 & $\begin{array}{l}\text { Right medial thigh rotation flap, left gracilis VY- } \\
\text { advancement flap }\end{array}$ & Nil \\
\hline 42 & 44 & Recurrent SCC vulva & Bilateral & 210 & Right stoma, bilateral gracilis VY-advancement flap & $\begin{array}{l}\text { Bilateral superficial tip necrosis of } \\
\text { the flaps }\end{array}$ \\
\hline 43 & 76 & Squamous cell carcinoma vulva & Bilateral & 300 & \multicolumn{2}{|c|}{$\begin{array}{l}\text { Right vertical rectus abdominis myocutaneous flap, Nil } \\
\text { left gracilis muscle flap and split skin graft }\end{array}$} \\
\hline
\end{tabular}


critical as we gradually adducted the hips in the course of closure to distribute wound tension. We avoided pole stirrups as the hips

\section{Fig. 2. Intraoperative positioning for vulvar reconstruction}

Intraoperative positioning of patient on Allen Yellofin stirrups. The knees are extended and stirrups hinged in a manner that allows adduction of the hips to reduce tension on the flaps during inset. The buttocks are exposed for the elevation of gluteal fold flaps in this case.

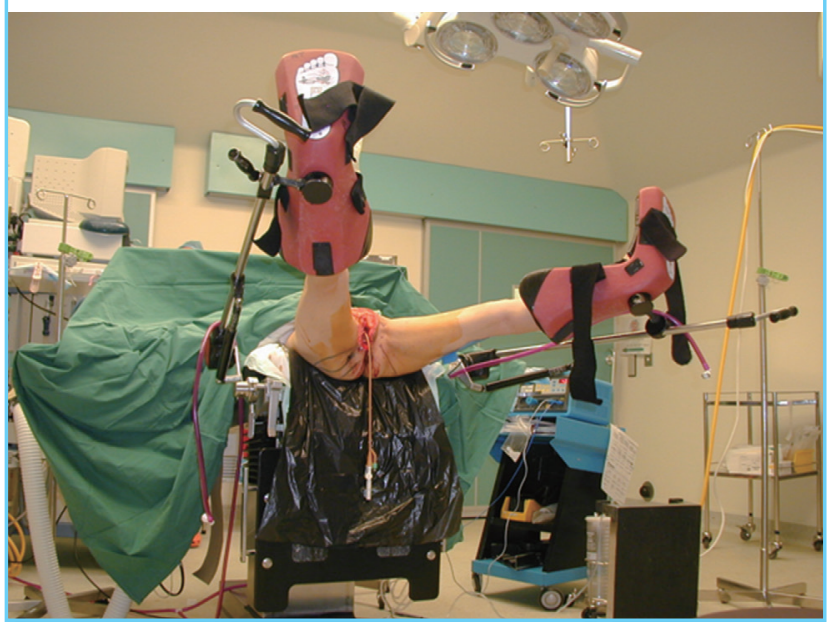

are unnaturally splayed, widening the wounds. 2) The urinary catheter was temporarily detached and plugged for ease of catheter manipulation during periurethral stitching. 3) When medial thigh flaps were used-gracilis included-the long saphenous vein with its perivascular lymphatics were preserved to minimize the risk of lymphedema. 4) When stitching a deep recess or around the urethra or anus, key stitches were placed and left untied initially. They were then sequentially tied once it was determined that all stitches were evenly distributed. Routinely, vicryl $2 / 0$ and $3 / 0$ were used. For skin grafting deep recesses, we liberally used fibrin glue to secure the skin graft without stitches. 5) Postoperatively the patient was nursed supine with an electric fan to aerate the perineum. She was nursed prone if the defect was predominantly posterior (case 40 ). Tetracycline $3 \%$ ointment was applied to the wounds liberally. For antibiotic prophylaxis, a combination of intravenous rocephine, flagyl, and cloxacillin, or intravenous tazocin alone were used.

\section{RESULTS}

There were no major acute complications such as flap loss,

\section{Fig. 3. A case of myocutaneous gracilis transposition flap}

Right vulvar squamous cell cancer in a 61-year-old (case 18). (A) Hemivulvectomy defect with pubic bone exposed and dead space to fill. (B) Right myocutaneous gracilis flap with its slender distal muscular end. (C) Flap was transposed and inset with distal muscle filling deep bony cavity; donor site was closed primarily; the result shown at one year postoperatively.
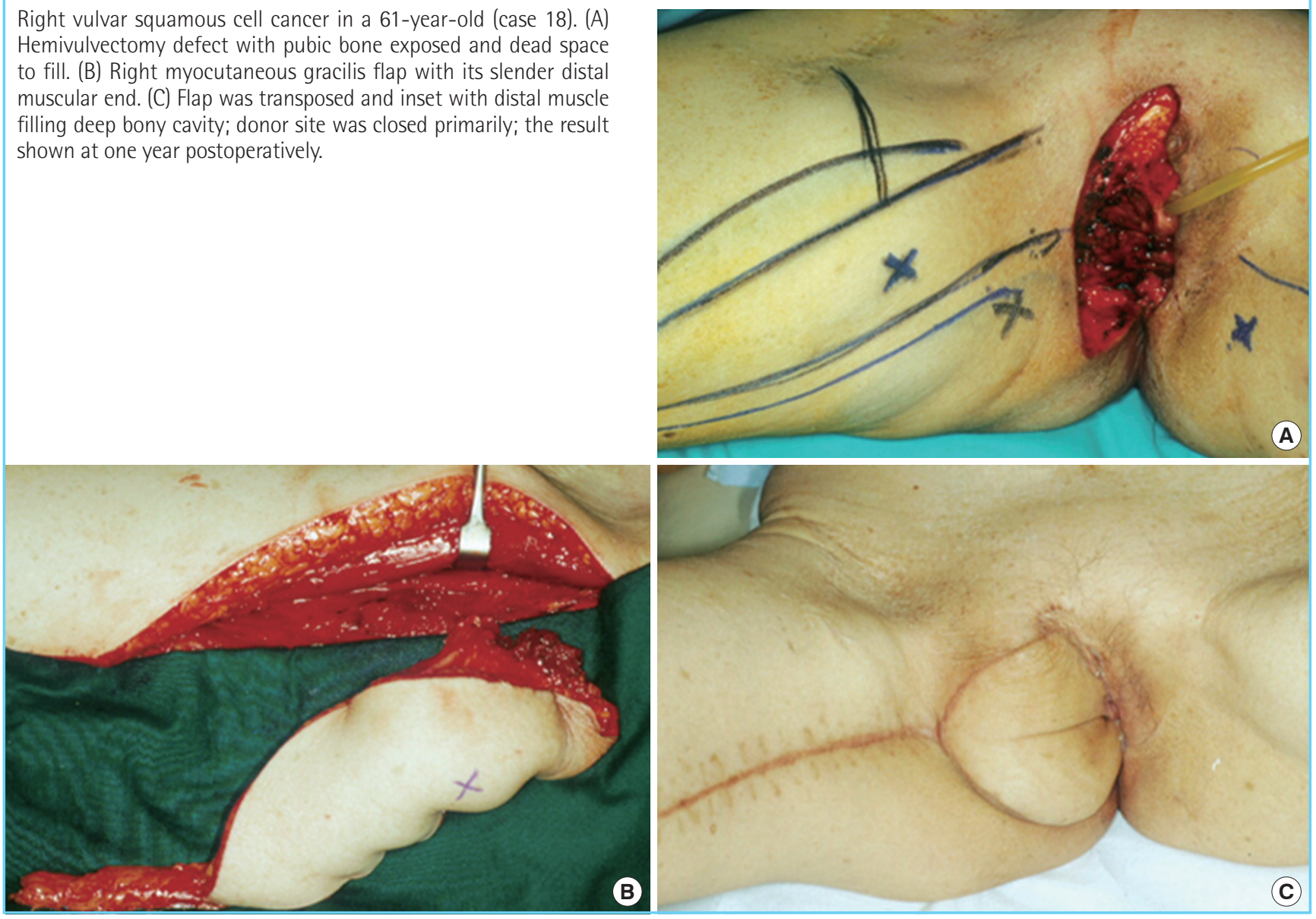
wound dehiscence, and urethral stenosis. Minor complications included celllulitis $(n=4)$ requiring prolonged antibiotic treatment, superficial tip necrosis of the flap $(n=3)$, long term hypertrophic and/or unaesthetic scarring of the donor site $(n=4)$, and anal contracture requiring regular dilatation (case 40). Twenty-two patients (51\%) were able to resume sexual intercourse. There were no problems with urination and urine flow in all our patients.

There was no difference in complications rates comparing unilateral and bilateral defect reconstruction. Adjuvant radiotherapy was required in 4 patients and it was commenced after all wounds had healed. There were no local complications of radiation therapy. Six patients died of causes related to metastatic complications of vulvar cancer in the follow-up period. The survival rate of our patients was $86 \%$ at a mean follow-up period of 30.2 months.

All patients were generally satisfied with the results of reconstruction. The younger patients who underwent gluteal fold flap reconstruction were particularly appreciative of the hidden gluteal crease scar.

\section{DISCUSSION}

The goals of reconstruction include: providing quality skin cover thus minimizing scarring and distortion, restoring the vaginal introitus and vault, and maintaining the central position of the urethral meatus and preventing stenosis.

Good quality reconstruction includes external cover and inner lining. External features that we attempted to recreate include the hair-bearing mons, symmetrical labial folds, and the ano-vaginal partition which prevented faecal passage into the vagina.

Defects of the vaginal wall and any exposed pubic bone will be overgrown with granulation tissue, scar down, and ultimately lead to obliteration of the vault. There must be adequate lining to keep the introitus and vagina patent, thereby allowing maintenance of hygiene and resumption of sexual intercourse for those sexually active [1]. Half of our patients were able to return to sexual activity. Durable skin around the urinary meatus prevents meatal stenosis and distortion allowing normal urinary flow without wetting the inner thigh. Finally, skin cover also facilitates healing and a smooth transition to adjuvant radiotherapy if needed.

\section{Fig. 4. A case of myocutaneous gracilis transposition flap}

Vulvar cancer in a 74-year-old (case 2). (A) Vulvectomy defect. (B) Left myocutaneous gracilis flap. (C) Flap was transposed and inset into defect and donor site was closed primarily; the result shown at one year postoperatively.
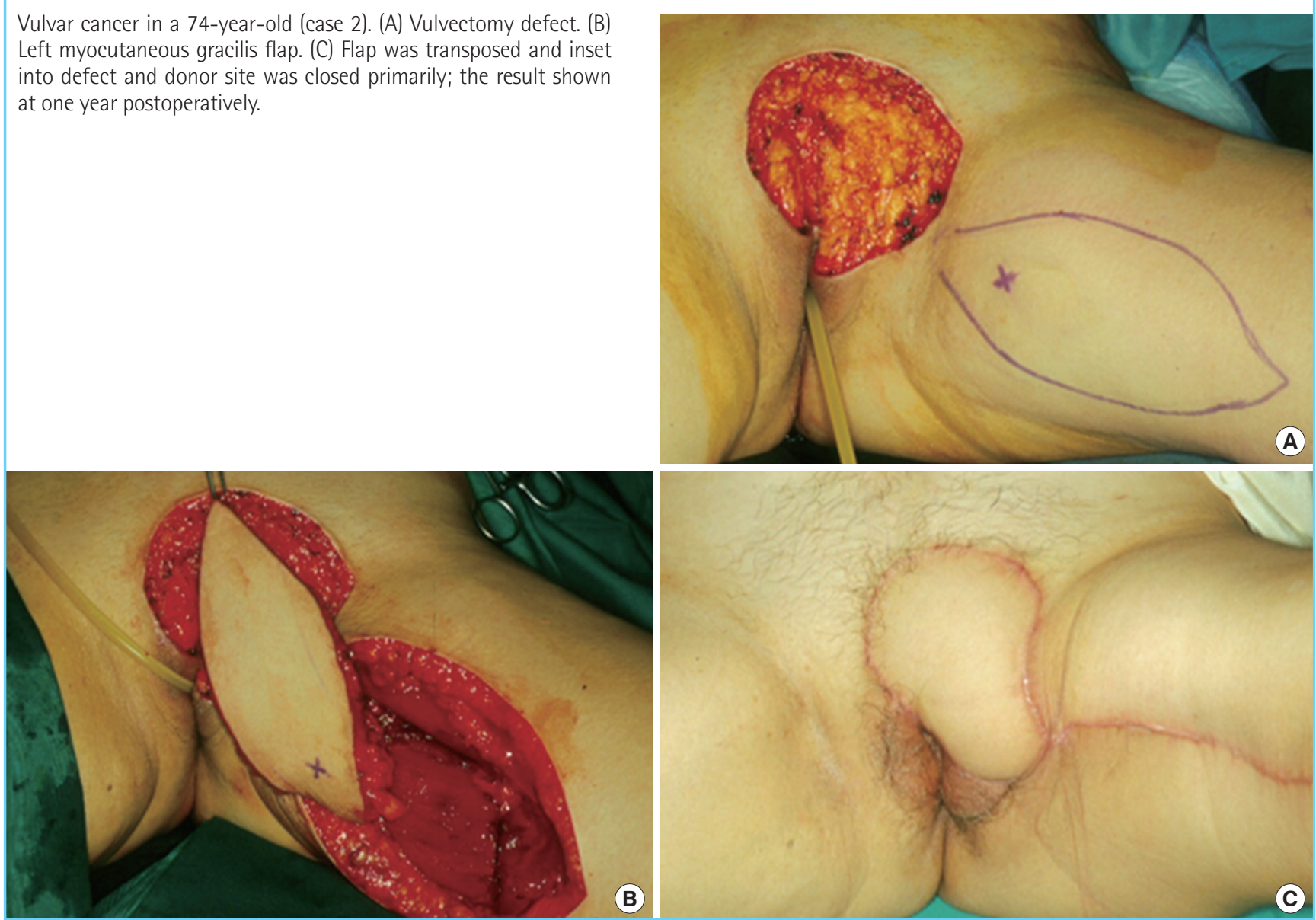
We have devised a reconstructive algorithm based on the size, location and depth of the vulvar defect (Fig. 1). Small vulvar defects were amenable to direct closure, skin grafting, and local flaps [4-6]. Any concomitant groin dissection would preclude the use of local flaps based on the superficial circumflex, epigastric and external pudendal arteries as these vessels would have been ligated. In this situation undermining and primary closure were preferred to fancy flaps (case 7).

The reconstructive needs in large defects include the need to fill dead space, cover the pubic bone (case 18) (Fig. 3) and line the periurethral area (cases 31, 32, 37). Large medial thigh rotation flaps and VY-advancement flaps fulfilled these needs well. In Paget's disease where reexcision is common because of involved margins, these flaps lent themselves well to repeat surgeries. The medial thigh VY-advancement flap has been described based on a subcutaneous pedicle, but in our experience, the same flap based on the medial femoral circumflex artery afforded better reach because it could be completely mobilized (Figs. 4, 5 showing respectively cases 2 and 34) [7]. A disadvantage of this flap was its tendency to pin-cushion and form hypertrophic borders (30\% of cases). The medial thigh rotation flap was an alternative for large defects and although primary closure was always achieved, the result was a long curvilinear scar (cases 20, 40, 41). In both instances we preserved the great saphenous vein with a cuff of adipose tissue to prevent lymphedema. We have used the anterolateral thigh flap (case 38) for extensive vulvar cancer but needed to skin graft the lateral thigh donor site.

Outer vaginal wall defects were easily covered with the super-
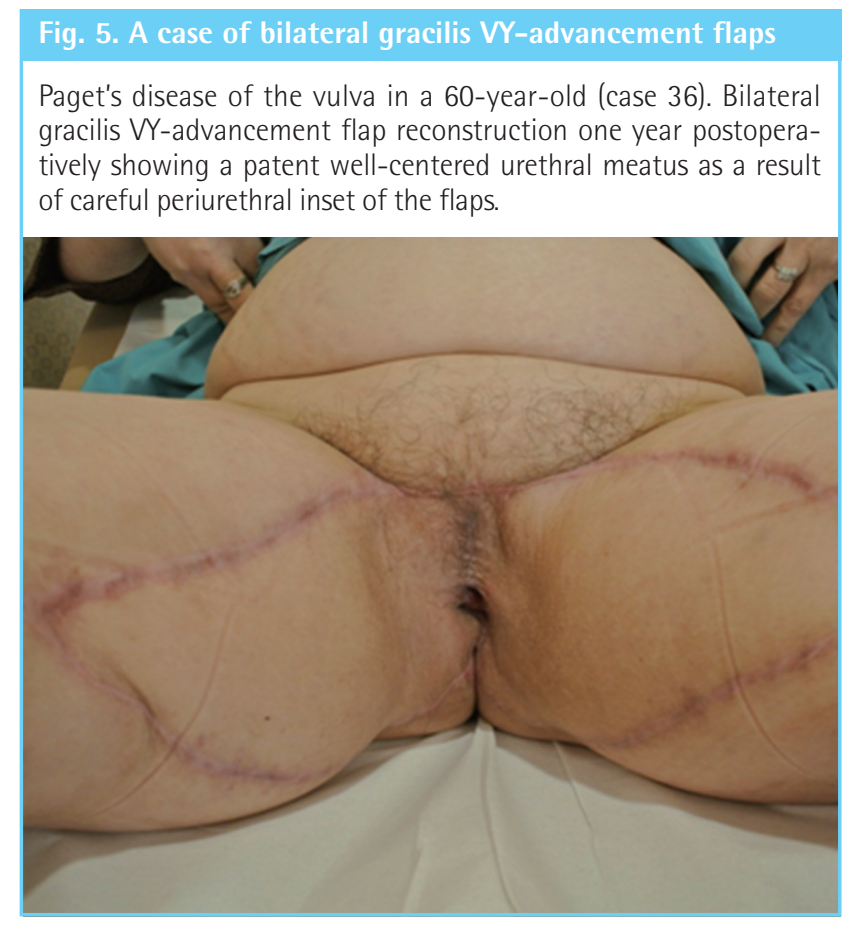

ficial portion of the above flaps. However with deep vaginal vault defects exposing the pubic bone, the medial thigh skin was too bulky to fit in, let alone stitch. Instead, the distal slender portion of the gracilis muscle was used with skin grafts overlaid for lining (case 18) (Fig. 3) [8,9]. We used fibrin glue to secure the skin graft as it was impossible to stitch in a deep recess.

The VRAM flap (case 22) (Fig. 6) was used in a case of radical vulvectomy with pubic ostectomy for sarcoma. In planning the surgery we persuaded the colorectal surgeon to site the end-colostomy on the right side (and not the usual left) so that we could use the ipsilateral VRAM flap for better reach. Ordinarily the VRAM flap is not used because of its bulkiness. Additionally it risked abdominal hernia formation because the flap is pivoted where the posterior rectus sheath is deficient. However we used the flap in this case for added volume [10].

The urethra meatus was involved and partially resected in 6 (29\%) of our 21 cases with extramammary Paget's disease. Three cases were surfaced with unilateral flaps and the rest were with bilateral flaps. The flap edge chosen had to be well-vascularized and thin, and periurethral inset was done meticulously with interrupted vicryl 3/0 sutures. If reconstruction was done with paired bilateral flaps, we took care to ensure that the meatus was circumferentially lined.

From an aesthetic viewpoint the gluteal fold flap (Figs. 7, 8 showing respectively cases 11 and 24) was superior because of the well-concealed donor scar $[11,12]$. However its reach was limited to the lower and middle thirds of the vulva. The gluteal fold flap was designed as a transposition or VY-advancement

\section{Fig. 6. A case of vertical rectus myocutaneous flap \\ Post-reconstruction with left vertical rectus myocutaneous flap at 6 months follow-up in a 45-year-old patient who had sarcoma (case 22). Note colostomy was sited to the right (instead of usual left) to facilitate optimal wound coverage with an ipsilateral rectus flap.}

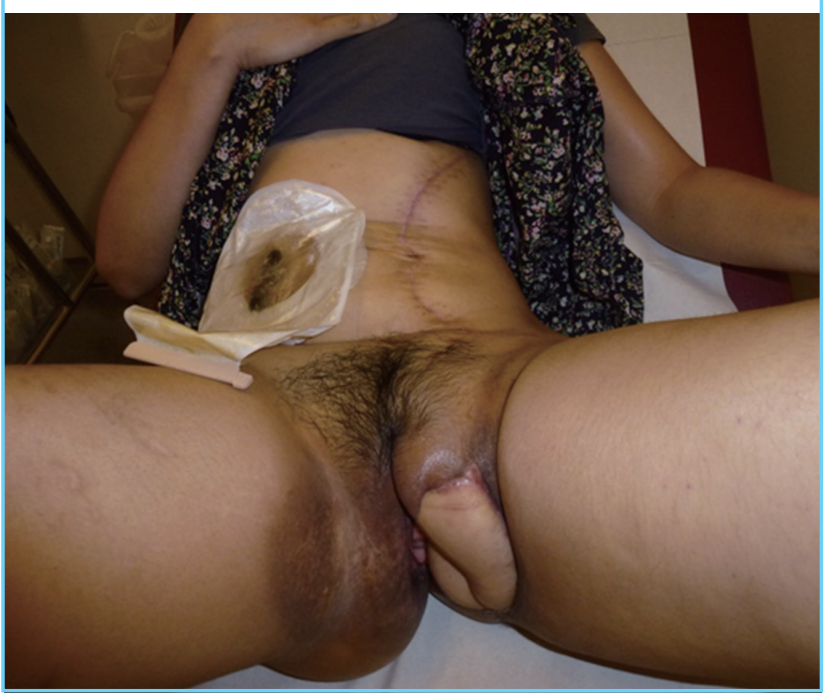


Fig. 7. A case of gluteal fold transposition flap

Paget's disease of the right vulva in a 63-year-old (case 11). (A) Vulvectomy defect with perforators dopplered. (B) Right gluteal fold flap. (C) Flap was transposed and inset into defect and donor site was closed primarily; the result shown at one year postoperatively with a well-concealed donor-site in the gluteal crease.
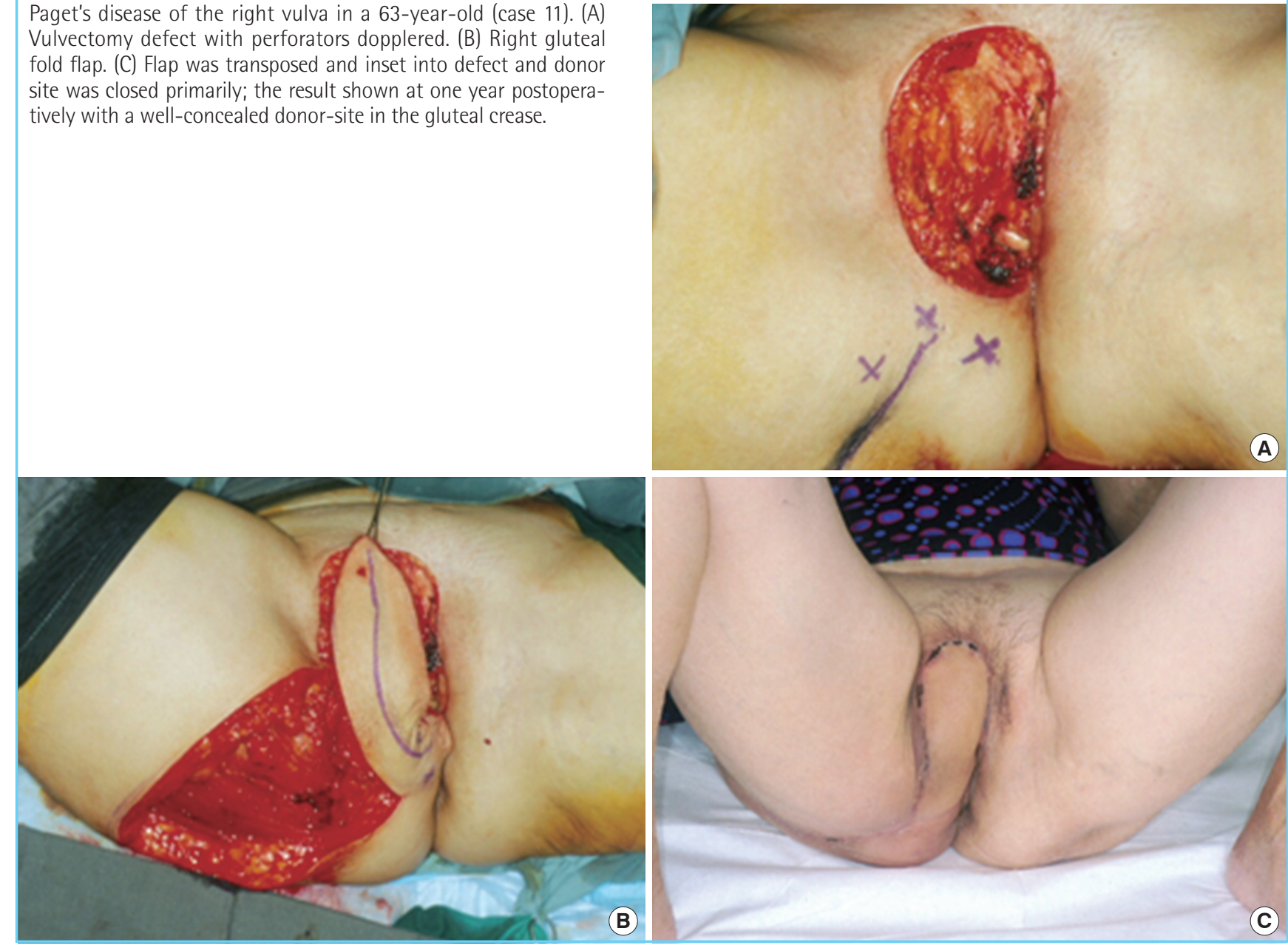

Fig. 8. A case of bilateral gluteal fold VY-advancement flaps

Post-reconstruction with bilateral gluteal fold VY-advancement flaps at 1 year follow-up in a 51-year-old patient (case 24) who had bilateral Paget's disease of the vulva.

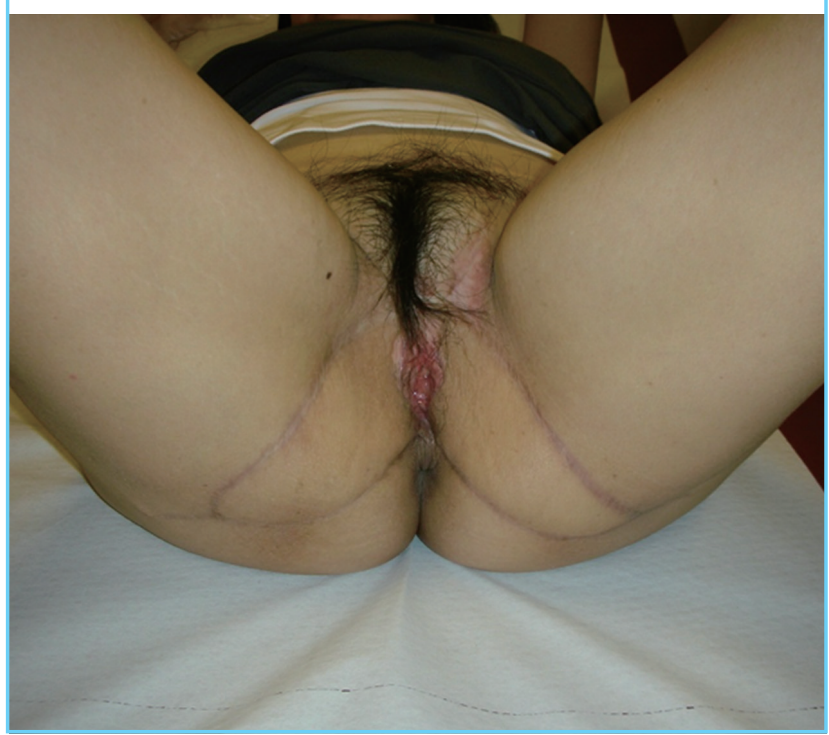

Fig. 9. A case of gracilis muscle flap and skin grafting

An 83-year-old patient (case 17) who had vulvar carcinoma. Postreconstruction with a right gracilis muscle flap and skin grafting; at one year follow-up showing a patent introitus and vaginal vault.

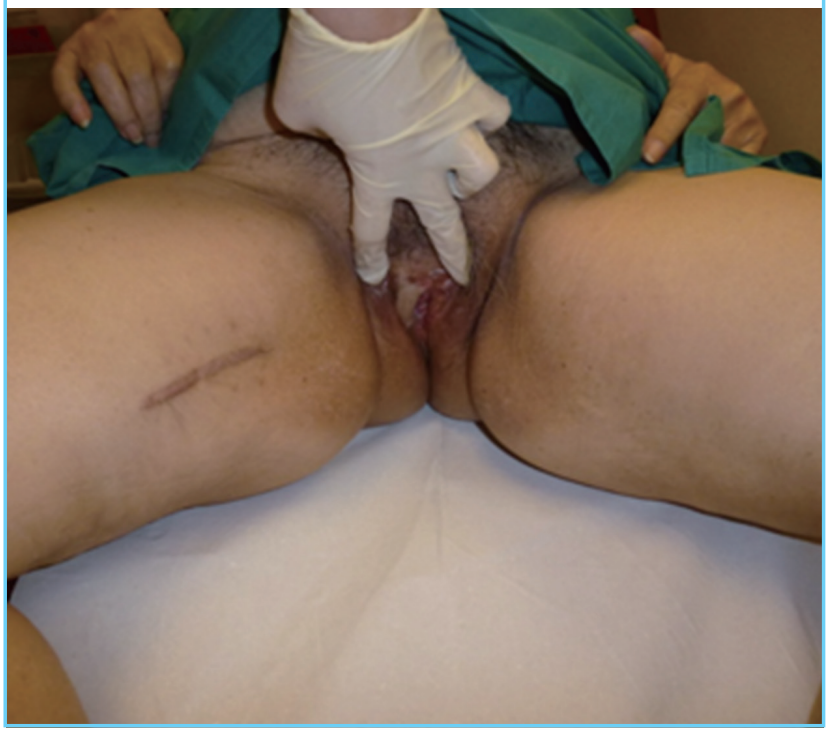


flap. For upper third defects, we preferred the gracilis myocutaneous transposition flap which left a short linear medial thigh scar (case 2) (Fig. 4). We had minimal complications with the gracilis and gluteal fold flaps (Table 1) and recommend their routine use as workhorse flaps for vulvar reconstruction.

Despite our elaborate reconstructive algorithm, the patients' age, body mass index, and comorbidities were taken into account. $60 \%$ of our patients were elderly (60 years and above) with multiple comorbidities such as ischemic heart disease and diabetes mellitus. Also $20 \%$ of our patients were severely obese. In these patients we preferred the gracilis muscle flap and skin grafting which was speedy, technically less demanding, and devoid of donor site morbidity (case 17) (Fig. 9).

\section{REFERENCES}

1. Hockel M, Dornhofer N. Vulvovaginal reconstruction for neoplastic disease. Lancet Oncol 2008;9:559-68.

2. Shamini N, Tay EH, Ho TH. Vulvar cancer: what do we know about our patients? Singapore Med J 2001;42:292-6.

3. Wang EC, Kwah YC, Tan WP, et al. Extramammary Paget disease: immunohistochemistry is critical to distinguish potential mimickers. Dermatol Online J 2012;18:4.

4. Rutledge F, Sinclair M. Treatment of intraepithelial carcinoma of the vulva by skin excision and graft. Am J Obstet Gy- necol 1968;102:807-18.

5. Julian CG, Callison J, Woodruff JD. Plastic management of extensive vulvar defects. Obstet Gynecol 1971;38:193-8.

6. Wee JT, Joseph VT. A new technique of vaginal reconstruction using neurovascular pudendal-thigh flaps: a preliminary report. Plast Reconstr Surg 1989;83:701-9.

7. Wang TN, Whetzel T, Mathes SJ, et al. A fasciocutaneous flap for vaginal and perineal reconstruction. Plast Reconstr Surg 1987;80:95-103.

8. McCraw JB, Massey FM, Shanklin KD, et al. Vaginal reconstruction with gracilis myocutaneous flaps. Plast Reconstr Surg 1976;58:176-83.

9. Chen SH, Hentz VR, Wei FC, et al. Short gracilis myocutaneous flaps for vulvoperineal and inguinal reconstruction. Plast Reconstr Surg 1995;95:372-7.

10. Shepherd JH, Van Dam PA, Jobling TW, et al. The use of rectus abdominis myocutaneous flaps following excision of vulvar cancer. Br J Obstet Gynaecol 1990;97:1020-5.

11. Hashimoto I, Nakanishi H, Nagae H, et al. The gluteal-fold flap for vulvar and buttock reconstruction: anatomic study and adjustment of flap volume. Plast Reconstr Surg 2001; 108:1998-2005.

12. Lee PK, Choi MS, Ahn ST, et al. Gluteal fold V-Y advancement flap for vulvar and vaginal reconstruction: a new flap. Plast Reconstr Surg 2006;118:401-6. 